\title{
An adaptation of DAPI-banding to fishes chromosomes
}

\author{
Pieczarka Julio Cesar*, Nagamachi Cleusa Yoshiko, Paes de Souza Augusto Cesar, \\ Milhomem Susana Suely Rodrigues, de Castro Roberta Rezende and Nascimento \\ Aline LiRA
}

Departamento de Genética — CCB; Universidade Federal do Pará; Campus do Guamá; Belém — PA — Brasil; $66075-110$

\begin{abstract}
This is the description of a method to obtain DAPI-banding in fishes' chromosomes by its denaturation using formamide. The slides are aged in an incubator and dehydrated in an ethanol series. The next step is the denaturation in formamide $70 \%$ and staining with DAPI. The pattern obtained is mostly C-band like, but matches only partially with the C-band pattern usually found by Barium Hydroxide technique. The bands obtained also do not match with the band pattern by $\mathrm{CMA}^{3}$. These data and a review of literature bring the conclusion that the banding is related to the DNA base composition instead of being related to the chromosome structural changes resulting from a long denaturation process.
\end{abstract}

Key words: banding; chromosome; DAPI; FISH; fluorochrome.

\section{INTRODUCTION}

Fluorochromes that link to DNA are useful in cytogenetic research. There are two kinds of fluorochromes in this category: those that are specific for the A-T DNA base-pairs and those specific for C-G. Stains like Hoechst 33258 and 4'-6diamidino-2-phenylindole (DAPI) link to A-T base pairs, while others like Quinacrine and Daunomycin have low base-pair specificity, but become fluorescent when linked to A-T. On both situations the banding pattern is Q-banding. Stains specific for C-G base-pairs, like Chromomycin $\mathrm{A}^{3}$, Mitramycin and Actinomycin $\mathrm{D}$, give R-banding pattern for they bright on C-G rich regions (review in SchweIzER 1981). The fluorochrome banding technique, introduced by CASPERSSON et al. $(1968 ; 1969)$ using Quinacrine (Q-banding) was a revolution on cytogenetics, for it allows the precise identification of the chromosome pairs. However, soon the Q-banding was replaced by G-banding since Quinacrine, as most fluorochromes, has low bands contrast and fades quickly with light excitation. For this reason the fluorescent banding techniques were left apart for many years. New methods were developed recently to overpass these problems, like the new

\footnotetext{
* Corresponding author: phone/fax: 8131-1931; e-mail: julio@ufpa.br
}

anti-fading solutions that solved the problem of the fluorochrome stability.

The advances of the Fluorescent In Situ Hybridization (FISH) technique in the last decade of the last century also contributed to the new interest on the use of fluorochromes. Heng \& Tsui (1993) reviewed the use of DAPI in FISH studies as a method of chromosome identification, since the denaturation of DNA by formamide improves the quality of DAPI banding. In that paper it is important to note that if formamide is used with the right time, it only denaturates the DNA and produces a banding pattern similar to Q-banding, while a longer exposition produces C-banding. In our own research in mammals using chromosome painting, we ordinarily use DAPI as a method of chromosome identification. As we use the DAPI as a counterstaining, the chromosomes were already submitted to formamide denaturation. We supposed that the formamide denaturation could help the DAPI banding in fishes. This is an interesting subject, since the DAPI banding found in birds and mammals it is not observed on fishes, where a uniform stain is the usual result (JANKUN et al. 1998; Margarido \& Galetti Junior 1999; Swarca et al. 2003; our unpublished data). Probably this is a result of the different structure of fish chromosomes when compared to birds and mammals. Another point is that fishes have huge karyotypic variation, with the diploid number ranging from $2 \mathrm{n}=22$ (Nannoplosmus unifasciatus) 
to $2 \mathrm{n}=134$ (Corydoras aeneus), according to PORTO et al. (1992). The study of this variation it is not easy since there are few useful chromosome markers for the study of this group of animals. Any new chromosome methodology on fishes would bring many new data, what makes interesting to have a working methodology for DAPI banding in fishes.

So we stained metaphases of some species of Amazon fishes with DAPI after their denaturation using the routine method that we use for mammals.

\section{MATERIAL AND METHODS}

We made metaphase preparations from some species of Neotropical fishes. We choose species from different taxonomic groups, to check out if the technique works on all of them: Platydoras aff. costatus (Family Doradidae, $2 \mathrm{n}=58$ ); Pterophyllum scalare (Family Cichlidae, $2 \mathrm{n}=52$ ); Oligansistrus sp (Family Loricariidae, $2 \mathrm{n}=52$ ); Hypostomus sp. (Family Loricariidae, $2 \mathrm{n}=64$ ) Gymnotus carapo (Family Gymnotidae, $2 \mathrm{n}=42$ ). The metaphase spreads were made following the air drying technique described by EgOzCUE (1971) and Cestari (1973), and changed by Bertollo (1978)

The DAPI banding technique here described needs that the metaphase spreads must be submitted to DNA denaturation. The slides were dehydrated in an ethanol series at room temperature: $2 \mathrm{x} 70 \%, 2 \mathrm{x} 90 \%$ (two minutes each), and $1 \mathrm{x}$ $100 \%$ (4 minutes). After air drying they were aged for one hour at $65^{\circ} \mathrm{C}$. Next they were immersed one minute in a coupling jar in the denaturation solution $(70 \%$ formamide, $30 \% 2 \mathrm{SSC})$ at $60^{\circ} \mathrm{C}$, and put immediately in ice cold $70 \%$ ethanol, for four minutes. After that, it was made another ethanol series at room temperature: $1 \times 70 \%$ and $2 \times 90 \%$ (two minutes each), 1x 100\% (four minutes). After air drying, the slides were covered with "Vectashield with DAPI H-1200" (Vector) and a coverslip sealed with enamel. The metaphases were analyzed on a Zeiss Axiophot fluorescence microscope. The images were obtained by an Axiocam digital camera and analyzed by the Axiovision software.

\section{RESULTS AND DISCUSSION}

This is the description of a method for adapting DAPI banding to fishes chromosomes after denaturation of the DNA by formamide. HENG \& Tsui (1993) made a controlled study on the effect of chromosomal denaturation on DAPI banding in human chromosomes, where they showed the progressive occurrence of three different kinds of bands. With a short denaturation time it is found Q-banding. With a longer denaturation time there is a partial C-banding (only some heterochromatic regions are visible) and, after some more time, $\mathrm{C}$ banding. The transition among these banding is irreversible, what let clear that the prolonged denaturation is followed by real alterations on the chromosome structure. This means that the first banding is related to the base composition of DNA, later moving to a banding related to the chromosomal alterations made by the denaturation. Since Dev et al. (1972) C-banding techniques using formamide are in use in mammals. Recently Fernandez et al. (2002) described some improvements in this methodology. In both examples the C-banded chromosomes were later stained with Giemsa, what confirms the observation that its structure was really modified, since Giemsa has not the tendency of association to a specific kind of DNA base-pair. To check out if a similar effect could be found in fishes, we submitted metaphases of the species Gymnotus carapo to one minute denaturation on the conditions described on Material and Methods. The banding pattern obtained is shown in the Figure 1a. If this banding were just the C-banding resulting from chromosomal denaturation, without being related to the base-pairs composition, the same banding pattern would be obtained after Giemsa staining. We inverted the DAPI pattern via software $(1 \mathrm{~b})$ and stained the metaphase with Giemsa (Figure $1 c)$. The patterns in $1 \mathrm{~b}$ and $1 \mathrm{c}$ are different: for instance, the centromeric band pointed by an arrow head is larger in $1 \mathrm{~b}$ than $1 \mathrm{c}$; also the chromosome pointed by an arrow in $1 \mathrm{~b}$ is banded while it is not in 1c. The slide was destained in hot water, useful for removing the immersion oil as well, and submitted again to a one minute denaturation, following the Material and Methods protocol. This time the C-banding pattern was more evident and the DAPI banding (Figure 1d) was different from the one obtained previously (1a). Again we inverted the DAPI pattern via software (1e) and stained the metaphase with Giemsa (Figure 1f). The patterns were more similar this time, what confirms that these last banding was a result of chromosomal alterations made by the long denaturation. It is necessary to note, however, that even in this second staining the DAPI does not perfectly match the C-bands, since the NOR region is im- 


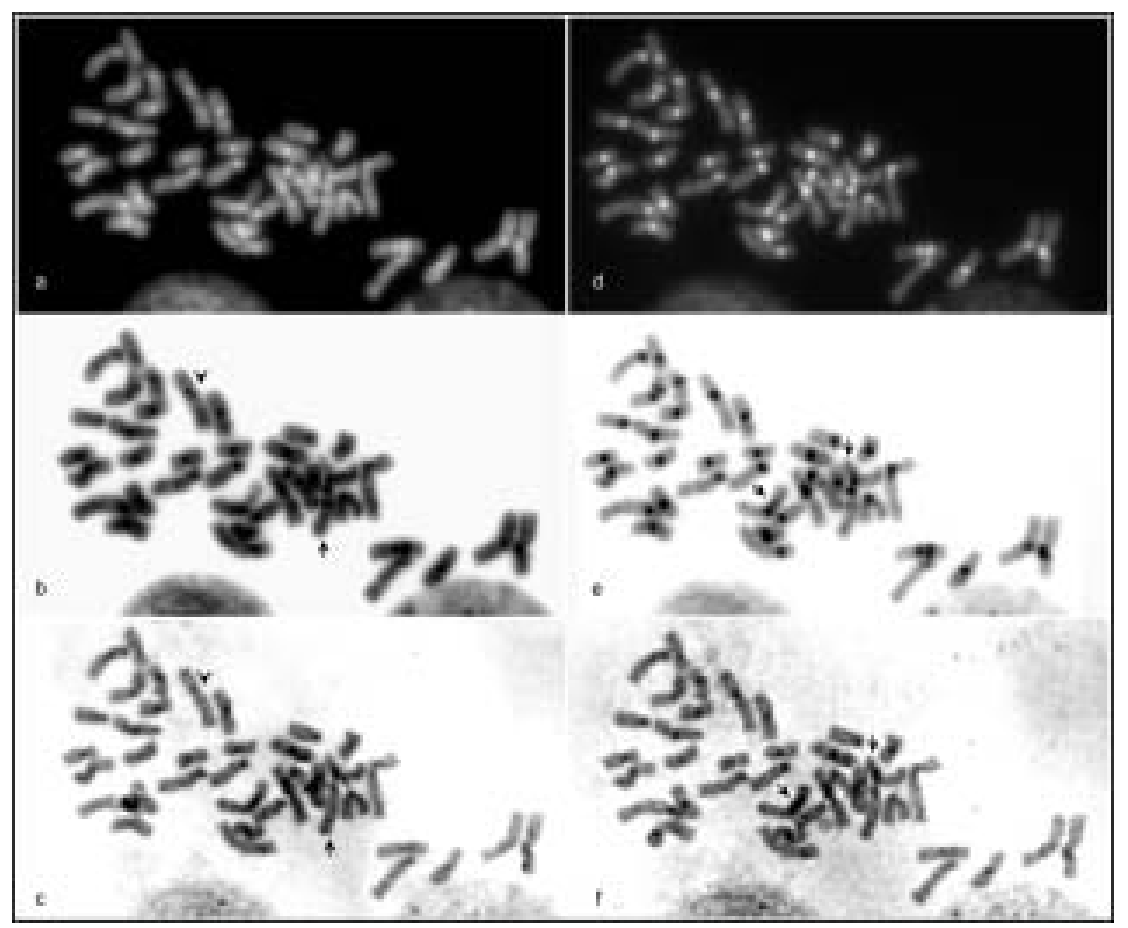

Fig. 1 - a) DAPI banding in Gymnotus carapo after one minute of denaturation; b) the same image digitally inverted; c) the same metaphase stained with Giemsa; d) DAPI banding in Gymnotus carapo after two minutes of denaturation; e) the same image digitally inverted; $f$ ) the same metaphase stained with Giemsa. The arrows heads in "b" and " $c$ " indicate the difference in size of the centromeric band; the arrows in " $b$ " and " $c$ " indicate the banding differences; the arrows in " $\mathrm{e}$ " and " $\mathrm{f}$ " indicate the NOR.
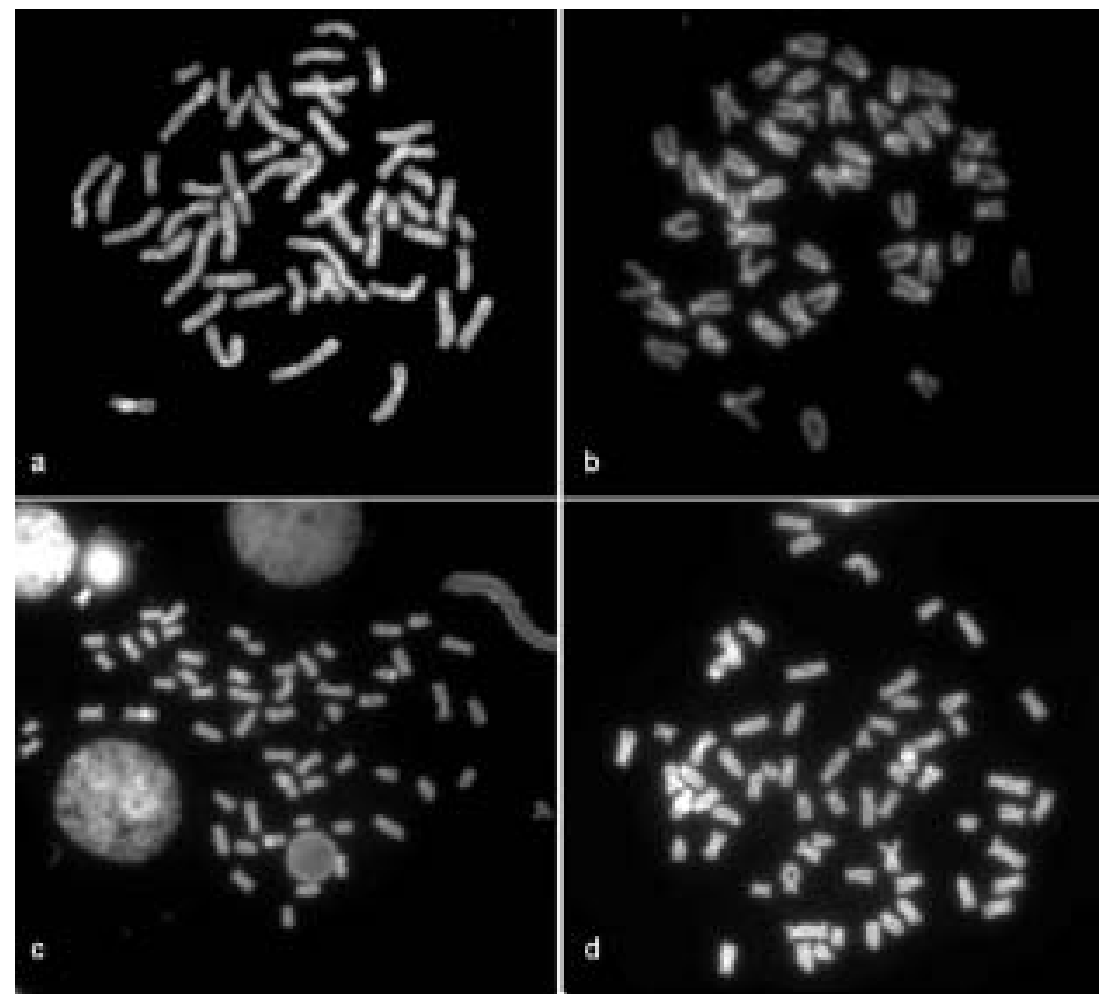

Fig. 2 - DAPI banding after one minute of denaturation in (a) Oligansistrus sp, (b) Pterophyllum scalare, (c) Platydoras aff. costatus, and (d) Hypostomus sp. 
mersed in a rich CG heterochromatic region that stains with Giemsa (arrows in 1f), but not with DAPI (arrows in 1e).

The figure 2 shows the banding on the species (a) Oligansistrus sp, (b) Pteropbyllum scalare, (c) Platydoras aff. costatus, and (d) Hypostomus sp respectively. The technique here described was not used in fishes yet. The data here presented let clear that the DAPI bands obtained are related to the base-pair composition, and would correspond to the first kind of banding (Q-banding) found in mammals by Heng \& Tsui (1993).

Acknowledgements - To the CNPq for Scholarships to the students Susana Suely Rodrigues Milhomem, Roberta Rezende de Castro and Aline Lira Nascimento.

\section{REFERENCES}

Bertollo L.A.C., 1978 - Estudos citogenéticos no gênero Hoplias Gill, 1903 (Pisces, Erythrinidae). PhD Thesis. Faculdade de Ribeirão Preto, Universidade de São Paulo, Ribeirão Preto.

Bertollo L.A.C., moreira-filho O. and Galetti Jr. P.M., 1986 - Cytogenetics and taxonomy: Considerations based on chromosome studies of freshwater fish. Journal of Fish Biology, 28:153-159.

Cestari A.N., 1973 - Métodos de estudos dos cromossomos de vertebrados. In: Azevedo JL, de Costa SOP (eds) Exercícios Práticos de Genética, Companhia Editora Nacional. Ed. Universidade de São Paulo. São Paulo pp 29-31.

Dev V.G., Miller D.A., Allder-Dice, P.W. and Miller O.J., 1972 - Method for locating the centromeres of mouse meiotic chromosomes and its application to $\mathrm{T} 163 \mathrm{H}$ and $\mathrm{T} 70 \mathrm{H}$ translocations. Experimental Cell Research, 73: 259-262.
Egozcue J., 1971 - Técnicas em citogenética. Ed. ESPAXS, Barcelona, 144 pp.

Fernandez R., Barragan M.J.L., Bullejos M., Marchal J.A., Diaz De La Guardia R. and Sanchez A., 2002 - New C-band protocol by heat denaturation in the presence of formamide. Hereditas, 137 : 145-148.

Heng H.H.Q. and Tsui L.C., 1993 - Modes of DAPI banding and simultaneous in situ bybridization. Chromosoma, 102: 325-332.

Jankun M., Woznicki P., Dajnovicz G., Demska-ZaKES K., LuCZYNski M.J. and LuCZYNSKi M., 1998 - Heterochromatin and NOR location in northern pike (Exos lucius). Aquatic Sciences, 60: 17-21.

Margarido V.P. and Galetti JR. P.M., 1999 - Heterochromatin patterns and karyotype relationships within and between the genera Brycon and Salminus (Pisces, Characidae). Genetics and Molecular Biology, 22 (3): 357-361.

Oliveira C., 1987 - Estudos citogenéticos no gênero Corydoras (Pisces, Siluriformes, Callichtbyidae). Mastership Dissertation. Instituto de Biociências, Universidade de São Paulo, SP.

Porto J.I.R., Feldberg E., Nakayama C.M. and FalCAO J.N., 1992 - A Checklist of chromosome number and karyotypes of Amazonian freshwater fishes. Revista de Hydrobiologia Tropical, 25 (4): 287-299.

SCHWEIZER D., 1980 - Simultaneous fluorescent staining of $R$ bands and specific beterochromatic regions (DA/DAPI bands) in buman chromosomes. Cytogenetics and Cell Genetics, 27: 190-193.

SCHWEIZER D., 1981 - Counterstain-Enhanced chromosome banding. Human Genetics, 57: 1-14.

Swarça A.C., Fenocchio A.S., Cestari M.M. and Dias A.L., 2003 - Analysis of heterochromatin by combination of C-banding and $C M A^{3}$ and DAPI staining in two fish species (Pimelodidae, Siluriformes). Genetica, 119 (1): 87-92.

Received 04.10.2005; accepted 15.01.2006 